\title{
Rabbit anti-thymocyte globulin induction in renal transplantation: review of the literature
}

This article was published in the following Dove Press journal:

Transplant Research and Risk Management

15 January 2014

Number of times this article has been viewed

\author{
Leah Andress' \\ Anjali Gupta ${ }^{2}$ \\ Nida Siddiqi ${ }^{3}$ \\ Kwaku Marfo 2,3 \\ 'University at Buffalo School \\ of Pharmacy and Pharmaceutical \\ Sciences, Department of Pharmacy \\ Practice, Buffalo, ${ }^{2}$ Montefiore \\ Medical Center, The University \\ Hospital for Albert Einstein \\ College of Medicine Department \\ of Abdominal Organ Transplant \\ Program, Bronx, ${ }^{3}$ Montefiore \\ Medical Center, Department of \\ Pharmacy, Bronx, NY, USA
}

Correspondence: Kwaku Marfo Montefiore Medical Center, I I I East 210th Street, Bronx, NY 10467, USA Email kmarfo05@gmail.com

\begin{abstract}
Rabbit anti-thymocyte globulin (rATG) has proven benefit as induction therapy in renal transplant recipients, achieving reduced acute rejection rates and better short-term allograft function, with slightly higher rates of complications such as infections and malignancy. Compared with other agents, the most benefit from rATG induction has been observed in renal transplant recipients at high immunologic risk for rejection. However, in special populations, such as pediatrics, the elderly, and hepatitis C-positive and human immunodeficiency virus-positive renal transplant recipients, additional information is needed to delineate the absolute benefit of rATG induction compared with other induction agents. Selection of rATG as the choice of induction therapy in renal transplant recipients should be guided by a cost-effective approach in balancing efficacy, safety, and cost. This review summarizes the published literature on efficacy, safety, and cost of rATG induction in renal transplantation.
\end{abstract}

Keywords: anti-thymocyte globulin, renal transplantation, induction therapy

\section{Introduction}

Nearly all renal transplant recipients require immunosuppressive therapy to prevent rejection. Antibody induction therapy often augments maintenance immunosuppression during and shortly after kidney transplantation. The current literature supports its use, particularly in patients at high immunologic risk for acute graft rejection and loss. Several antibody induction agents are available, and selection of induction agent and regimen remains controversial. Comparison of agents based on clinical studies can be challenging, given that studies are often conducted in patients of differing immunologic risk and using diverse maintenance immunosuppressive regimens. Comorbid diseases and financial constraints may also vary significantly between patients. These factors should all be considered when selecting the most appropriate induction agent and regimen for renal transplant recipients.

Antibody induction agents are divided into two broad categories, based on their activity on T-lymphocytes, as lymphocyte-depleting antibodies and nondepleting antibodies (Table 1). Lymphocyte-depleting antibodies, including rabbit anti-thymocyte globulin (rATG), equine anti-thymocyte globulin (eATG), monomurab-CD3 (OKT3), and alemtuzumab, are generally recommended in patients at high immunologic risk of rejection. Possible benefits of intense immunosuppression must be balanced with increased risks of infection and malignancy. On the other hand, nondepleting antibodies, including basiliximab and daclizumab, reduce the risk of acute allograft rejection with less intense adverse effects, and are typically used in patients at lower risk of acute rejection. The current Kidney Disease: Improving Global Outcomes guidelines 
Table I Lymphocyte depleting and nondepleting induction agents

\begin{tabular}{|c|c|c|c|c|}
\hline Agent & $\begin{array}{l}\text { Alternative } \\
\text { name(s) }\end{array}$ & Drug class & $\begin{array}{l}\text { Proposed mechanism(s) } \\
\text { of action }\end{array}$ & Serious adverse effects \\
\hline \multicolumn{5}{|c|}{ Lymphocyte-depleting } \\
\hline $\begin{array}{l}\text { Anti-thymocyte } \\
\text { globulin, rabbit } \\
\text { Anti-thymocyte } \\
\text { globulin, equine }\end{array}$ & $\begin{array}{l}\text { rATG, } \\
\text { Thymoglobulin }^{\circledR} \\
\text { eATG, Atgam }\end{array}$ & $\begin{array}{l}\text { Chimeric (rabbit) } \\
\text { polyclonal antibodies } \\
\text { Chimeric (equine) } \\
\text { polyclonal antibodies }\end{array}$ & $\begin{array}{l}\text { Exact mechanisms unknown; broadly } \\
\text { targets and eliminates preactivated, } \\
\text { noncycling memory lymphocytes; } \\
\text { alters T-lymphocyte activation, } \\
\text { homing, and cytotoxic function }\end{array}$ & $\begin{array}{l}\text { Cytokine release syndrome } \\
\text { (fever, shivering, myalgia, } \\
\text { headache), hypertension, } \\
\text { anemia, leukopenia, } \\
\text { thrombocytopenia, }\end{array}$ \\
\hline Alemtuzumab & Campath $^{\circledast}$ & $\begin{array}{l}\text { Humanized monoclonal } \\
\text { antibody against CD52 }\end{array}$ & $\begin{array}{l}\text { Targets most mature some immature } \\
\text { lymphocytes; exact mechanism } \\
\text { unknown, but may cause antibody- } \\
\text { dependent lysis of cells following } \\
\text { cell surface binding }\end{array}$ & increased risk of infection \\
\hline Muromonab-CD3 & OKT3, Orthoclone ${ }^{\circledR}$ & $\begin{array}{l}\text { Chimeric (murine) } \\
\text { monoclonal antibody } \\
\text { against CD3 }\end{array}$ & $\begin{array}{l}\text { Broadly targets all circulating } \\
\text { T-lymphocytes; promotes antibody- } \\
\text { mediated activation of complement } \\
\text { and apoptosis of T-lymphocytes }\end{array}$ & \\
\hline \multicolumn{5}{|c|}{ Lymphocyte nondepleting } \\
\hline $\begin{array}{l}\text { Daclizumab } \\
\text { Basiliximab }\end{array}$ & $\begin{array}{l}\text { Zenapax }^{\circledR} \\
\text { Simulect }\end{array}$ & $\begin{array}{l}\text { Chimeric (murine) } \\
\text { monoclonal antibody } \\
\text { against CD25 IL-2 } \\
\text { receptor }\end{array}$ & $\begin{array}{l}\text { Specifically targets } \mathrm{T} \text { cells that have } \\
\text { been activated by an MHC-antigen } \\
\text { stimulus; inhibits T-lymphocyte } \\
\text { activity }\end{array}$ & $\begin{array}{l}\text { Cytokine release syndrome } \\
\text { (fever, shivering, myalgia, } \\
\text { headache), hypertension, } \\
\text { anemia, leukopenia, } \\
\text { thrombocytopenia, } \\
\text { increased risk of infection }\end{array}$ \\
\hline
\end{tabular}

Abbreviations: eATG, equine anti-thymocyte globulin; IL-2, interleukin-2; MHC, major histocompatibility complex; rATG, rabbit anti-thymocyte globulin; CD, cluster of differentiation.

recommend use of rabbit anti-thymocyte globulin as induction therapy in renal transplant recipients at high immunologic risk for acute allograft rejection. ${ }^{1}$ The following review examines the current literature on the efficacy and outcomes of rATG induction and other available/historically significant induction agents in renal transplant recipients (Table 2).

\section{Prevention of rejection Mechanism of action}

rATG (Thymoglobulin ${ }^{\circledR}$ ) is a lymphocyte-depleting polyclonal antibody indicated for the treatment of acute renal allograft rejection, and its use in transplant induction is off-label. ${ }^{2}$ The precise mechanisms underlying the therapeutic efficacy of rATG are not entirely known, although T-cell depletion plays a critical role. Both in vitro and in vivo studies have suggested a number of other possible mechanisms, including lymphocyte surface antigen modulation and transcription factor activation. ${ }^{3-9}$ rATG may disrupt immune cell processes, such as cytokine production, chemotaxis, endocytosis, stimulation and proliferation, and leukocyteendothelial cell adhesion. rATG may also promote cell death via induction of apoptosis, antibody-dependent lysis, and complement-mediated lysis of various immune cells (Table 3). ${ }^{4,5,89}$ Figure 1 depicts the mechanism of action of alternative induction agents from rATG.

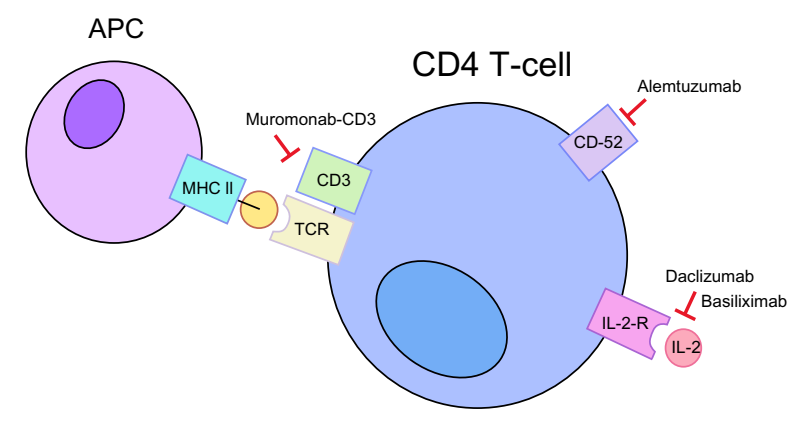

Figure I Alternative induction agents and cellular binding sites.

Abbreviations: APC, antigen-presenting cell; MHC II, major histocompatibility complex II; IL-2, interleukin-2; IL-2-R, interleukin-2 receptor; TCR, T-cell receptor; $\mathrm{CD}$, cluster of differentiation..

\section{Dosing and administration}

Because use of Thymoglobulin in induction therapy is offlabel, and US Food and Drug Administration approval is limited to treatment of acute rejection of renal transplant, the manufacturer's dosing suggestions are limited to treatment of acute rejection in adults, ie, $1.5 \mathrm{mg} / \mathrm{kg} /$ day for 7-14 days. ${ }^{2}$

Various strategies for rATG induction have been proposed and may vary based on cumulative dose, timing of first dose, and duration of therapy. ${ }^{10-12}$ The efficacy of 3-day induction was evaluated by comparing outcomes in 40 renal transplant recipients with a historic group of 48 patients who underwent a 7-day induction. ${ }^{10}$ The 3 -day course was administered as a single $3 \mathrm{mg} /$ $\mathrm{kg}$ intraoperative dose followed by $1.5 \mathrm{mg} / \mathrm{kg}$ on postoperative 
Table 2 Efficacy outcomes of rATG induction versus alternative regimens

\begin{tabular}{|c|c|c|c|c|c|c|}
\hline Reference & $\begin{array}{l}\text { Treatment (mg/kg/day, } \\
\text { unless noted otherwise) }\end{array}$ & $\mathbf{n}$ & $\begin{array}{l}\text { Time of } \\
\text { assessment (years) }\end{array}$ & BCAR (\%) & $\begin{array}{l}\text { Patient } \\
\text { survival (\%) }\end{array}$ & $\begin{array}{l}\text { Graft } \\
\text { survival (\%) }\end{array}$ \\
\hline \multicolumn{7}{|c|}{ Versus noninduction regimens } \\
\hline \multirow[t]{3}{*}{ Charpentier et al ${ }^{17}$} & rATG $1.25+$ TAC 0.3 PO $^{a}$ & 186 & 0.5 & $15^{* *}$ & 98.4 & 95.2 \\
\hline & rATG I. $25+$ CsA PO & 184 & 0.5 & 21.2 & 97.0 & 90.8 \\
\hline & TAC $0.3 \mathrm{PO}$ & 185 & 0.5 & 25.4 & 97.0 & 95.2 \\
\hline \multirow[t]{2}{*}{ Mourad et al ${ }^{18}$} & rATG $1.25+$ TAC $0.2^{\mathrm{a}}$ & $|5|$ & 1 & $15.2^{* *}$ & 97.4 & 92.1 \\
\hline & TAC 0.2 & 158 & 1 & 30.4 & 96.8 & 91.1 \\
\hline \multicolumn{7}{|l|}{ Versus BAS } \\
\hline \multirow[t]{4}{*}{ Lebranchu et al $\left.\right|^{5, * * * * *}$} & rATG I-I.5 & 50 & 0.5 & 8 & 100 & 100 \\
\hline & & & 1 & 8 & 100 & 96 \\
\hline & BAS $20 \mathrm{mg}$ on days 0 and $4^{b}$ & 50 & 5 & 8 & 98 & 96 \\
\hline & & & 10 & 8 & 98 & 96 \\
\hline \multirow[t]{2}{*}{ Mourad et $\mathrm{a}^{22}$} & rATG I & 53 & 1 & 9.4 & 98.1 & 96.2 \\
\hline & BAS $20 \mathrm{mg}$ on days 0 and $4^{\mathrm{b}}$ & 52 & 1 & 9.6 & 98.1 & 94.2 \\
\hline \multirow[t]{2}{*}{ Brennan et $\mathrm{al}^{21, \mathrm{c}}$} & rATG I.5 & $|4|$ & 1 & $15.6 *$ & 95.7 & 90.8 \\
\hline & BAS $20 \mathrm{mg}$ on days 0 and 4 & 137 & 1 & 25.5 & 95.6 & 89.8 \\
\hline \multirow[t]{2}{*}{ Haririan et $\mathrm{al}^{23}$} & ATG 1.5 & 36 & 1.5 & 14 & 94 & 91 \\
\hline & BAS $20 \mathrm{mg}$ on days 0 and 4 & 52 & 1.5 & 29 & 88 & 91 \\
\hline \multicolumn{7}{|l|}{ Versus eATG } \\
\hline \multirow[t]{4}{*}{ Brennan et $\mathrm{al}^{27}$} & rATG I.5 & 48 & 0.5 & 4 & 98 & - \\
\hline & & & 1 & 4 & 98 & $98^{*}$ \\
\hline & & & 5 & 8 & 85 & $77^{*}$ \\
\hline & & & 10 & 11 & 75 & 48 \\
\hline \multirow[t]{4}{*}{ Hardinger et $\mathrm{al}^{25,26, \mathrm{~d}}$} & eATG I5 & 24 & 0.5 & 17 & 96 & - \\
\hline & & & 1 & 25 & 96 & 83 \\
\hline & & & 5 & 34 & 71 & 54 \\
\hline & & & 10 & 42 & 67 & 50 \\
\hline \multicolumn{7}{|c|}{ Versus alemtuzumab } \\
\hline \multirow[t]{2}{*}{ Farney et $\mathrm{al}^{29,30, \mathrm{e}}$} & rATG 1.5 & 50 & 0.5 & 20 & 100 & 96 \\
\hline & $\begin{array}{l}\text { Alemtuzumab } 30 \mathrm{mg} \text { single } \\
\text { dose }\end{array}$ & 48 & & 0 & 98 & 95 \\
\hline
\end{tabular}

Notes: atreatment groups received rATG induction and delayed start TAC; bafter first dose, subsequent dosage adjustments maintained CD2+ or CD3+ T-cell counts $<20 / \mathrm{mm}^{3}$; 'patients at high risk of acute rejection or delayed graft function; ${ }^{d}$ patient population was African-American; ${ }^{677 \%}$ of patients underwent kidney transplants alone, $17 \%$ underwent pancreas-kidney transplants, and $4 \%$. Underwent pancreas after kidney transplant. $* P<0.05$ versus comparator(s); $* * p<0.01$ versus comparator(s); $* * * *$ trial was not sufficiently powered to test comparative efficacy.

Abbreviations: BAS, basiliximab; BCAR, biopsy-confirmed acute rejection; CsA, cyclosporine; DAC, daclizumab; eATG, equine anti-thymocyte globulin; MMF, mycophenolate mofetil; n, number of patients; PO, oral; rATG, rabbit anti-thymocyte globulin; TAC, tacrolimus.

days 1 and 2, while the 7-day course consisted of $1.5 \mathrm{mg} / \mathrm{kg}$ intraoperatively followed by six additional daily doses of the same size. At one year post transplant, there were no significant differences in frequency of acute rejection episodes, graft survival, or patient survival. ${ }^{10}$ However, there was a significantly shorter duration of initial hospital stay ( 6.1 days versus 8 days) and more sustained lymphocyte depletion with 3-day induction. ${ }^{10}$ Intraoperative administration was evaluated in a second, randomized, prospective study of 58 cadaveric renal transplant recipients who received either intraoperative or postoperative rATG induction therapy. ${ }^{11}$ The total number of rATG doses were equal between the treatment groups, and intraoperative dosing resulted in significantly fewer cases of delayed graft function, lower mean serum creatinine on postoperative days 10 and 14 , and a shorter duration of hospital stay $(P<0.05) .{ }^{11}$ There was no difference in incidence of cytomegalovirus infection.
rATG regimens ranging from $1 \mathrm{mg} / \mathrm{kg}$ to $6 \mathrm{mg} / \mathrm{kg}$ per dose for durations from one to 10 days have been studied in clinical settings. In high-risk patients, regimens providing cumulative doses of less than $7.5 \mathrm{mg} / \mathrm{kg}$ produced immunosuppressive results similar to regimens providing greater than $7.5 \mathrm{mg} /$ $\mathrm{kg}$, but with lower rates of infection and less development of lymphoma. ${ }^{13}$ At the lower end, cumulative doses of less than 3 $\mathrm{mg} / \mathrm{kg}$ have been shown to be ineffective at preventing acute rejection. ${ }^{11}$ The literature suggests that induction totaling 6 $\mathrm{mg} / \mathrm{kg}$, administered in divided doses of $1-2 \mathrm{mg} / \mathrm{kg}$ over 3-5 days, may provide the best balance of immunosuppression and risk of infection. ${ }^{10,11,14-16}$

\section{rATG induction versus no induction}

Two large, randomized controlled trials have examined rATG induction regimens versus noninduction regimens 
Table 3 Mechanisms of action of rabbit anti-thymocyte globulin

\begin{tabular}{ll}
\hline $\begin{array}{l}\text { Profound } \\
\text { lymphocyte } \\
\text { depletion }\end{array}$ & - Primary mechanism for rATG \\
immunosuppressive activity \\
- \\
aepletes T-cell via complement-dependent lysis \\
and T-cell activation and apoptosis \\
- Mechanism for this activity is not well \\
understood \\
- Modulates key cell-surface adhesion (CDI la/ \\
CDI8 integrin) and chemokine receptors \\
modulation & - Limits cellular infiltration following post- \\
& ischemic reperfusion \\
Apoptosis/ & Induces apoptosis in naïve B-cells, activated \\
cell lysis & B-cells, and bone marrow plasma cells \\
& Targets cell surface proteins CD I9, CD20, \\
CD80, CD40, CD38, and CDI38 & Interferes with dendritic cell maturation and \\
Other & migration \\
& Induction of regulatory T-cells and natural killer \\
& T-cells by targeting GITR, CTLA-4, and Foxp3 \\
\hline
\end{tabular}

Notes: Unlike monoclonal antibody preparations, polyclonal rATG antibodies target a wide range of immune cell surface antigens, with broad effects on the immune cells; rATG antibodies are known to target T-cells, natural killer cells, B-cells, plasma cells, adhesion molecules, and chemokine receptors. ${ }^{3,6,7}$

Abbreviations: rATG, rabbit anti-thymocyte globulin; CD, cluster of differentiation; GITR, glucocorticoid-induced tumor necrosis factor receptor; Foxp3, Forkhead box P3; CTLA, cytotoxic T lymphocyte-assorted antigen.

in the prevention of renal allograft rejection in adult renal transplant recipients. ${ }^{17,18} \mathrm{~A}$ three-arm, open-label study compared 555 renal transplant patients who randomly received either tacrolimus triple therapy, ATG induction with tacrolimus, or ATG induction with cyclosporine microemulsion. ${ }^{17}$ There were no differences between the treatment groups with regard to mean cold ischemia time, cytomegalovirus status of donor and recipient, or values for human leukocyte antigen mismatch. The number of patients with a panel reactive antibody grade greater than $50 \%$ was significantly higher only in the ATG with cyclosporine group $(P=0.044)$. All patients received concomitant azathioprine and corticosteroids. Results from this study suggest that addition of ATG induction to tacrolimus immunosuppressive therapy (delayed tacrolimus therapy) leads to significantly fewer cases of biopsy-confirmed acute rejection (BCAR) at 6 months post-transplant. ${ }^{17}$ The incidence did not differ significantly between tacrolimusbased therapy with ATG induction and cyclosporine-based therapy with ATG induction, although between these two groups, the incidence of moderate or severe rejection was more common with the cyclosporine-based regimen (13.6\% versus $5.4 \%, P<0.023$ ).

A second clinical trial, comparing ATG induction and delayed tacrolimus therapy against immediate tacrolimusbased triple therapy, also found lower rates of BCAR with ATG induction at 12 months post-transplant. ${ }^{18}$ However, neither of these trials reported differences in overall patient or graft survival at 6 and 12 months with ATG induction, and ATG induction did not significantly impact development of delayed graft function or mean serum creatinine levels at 6 and 12 months. Neither study accounted for differences in donor kidneys (living versus deceased) or donor criteria (standard versus expanded) as possible confounding variables.

\section{rATG induction versus nondepleting agents}

Two interleukin-2 receptor antagonists have historically comprised the nondepleting induction therapy options, ie, daclizumab (Zenapax ${ }^{\circledR}$ ) and basiliximab $\left(\right.$ Simulect $\left.^{\circledR}\right)$. A 2004 meta-analysis of 117 reports of 38 trials examined the efficacy of interleukin-2 receptor antagonist induction therapy. ${ }^{19}$ Compared with placebo, interleukin-2 receptor antagonists did not significantly reduce graft loss at one or 3 years post-transplant. Acute rejection was significantly reduced at 6 months (12 trials: relative risk [RR] 0.66, confidence interval [CI] 0.59-0.74) as well as one year (ten trials: RR 0.67, CI 0.60-0.75). Rates of cytomegalovirus infection and malignancy were not significantly reduced at one year. When compared with other antibody therapies, non-interleukin-2 receptor antagonist antibody therapies showed lower rates of biopsy-diagnosed acute rejection, graft loss/death, all-cause mortality, and delayed graft function. Interleukin-2 receptor antagonists were associated with lower rates of adverse effects. The researchers concluded that there was no definite improvement in graft or patient survival and no apparent differences between basiliximab and daclizumab.

In September 2009, Roche announced its voluntary discontinued production of daclizumab due to the availability of alternative induction agents and limited market demand for daclizumab. ${ }^{20}$

Basiliximab is a chimeric mouse-human monoclonal antibody to the alpha chain of the interleukin-2 receptor of T-cells and is the only nondepleting agent currently on the market. Several studies have shown basiliximab to be less effective than rATG in preventing acute rejection in renal transplant recipients at increased risk of rejection. A prospective, multicenter trial assessed the safety and efficacy of basiliximab $(\mathrm{n}=137) 20 \mathrm{mg}$ given on postoperative days 0 and 4 versus rATG ( $\mathrm{n}=141) 1.5 \mathrm{mg} / \mathrm{kg}$ given on days $0-4$ (total $7.5 \mathrm{mg} / \mathrm{kg}$ ) as induction therapy in renal transplant recipients at high-risk for acute rejection or delayed graft function. ${ }^{21}$ "High-risk" was defined by cold 
ischemia time and specific donor/recipient factors. All patients received cyclosporine $\mathrm{A}\left(\mathrm{Neoral}^{\circledR}\right)$, mycophenolate mofetil, and corticosteroid taper, with cytomegalovirus prophylaxis given in patients with seropositive donor and/or recipient status. Antifungal and antibacterial prophylaxis was administered as per each center's protocol. At the end of 12 months of follow-up, the overall incidence of first occurrence of biopsy-proven acute rejection (BPAR), delayed graft function, graft loss, or death was similar between the basiliximab and rATG groups (56.2\% versus 50.4\%, $P=0.34)$. The BPAR rate was higher in the basiliximab group $(25.5 \%)$ than in the rATG group (15.6\%), and this difference was statistically significant $(P=0.02) .{ }^{21}$ In addition, rejection requiring antibody treatment was more common in the basiliximab group than in the rATG group $(8.0 \%$ versus $1.4 \%, P=0.005) .{ }^{21}$ However, the incidence of delayed graft function was similar between the basiliximab and rATG groups (44.5\% and $40.4 \%$, respectively, $P=0.54$ ). Occurrence of infection was higher in the rATG group when compared with the basiliximab group ( $85.8 \%$ versus $75.2 \%, P=0.03$ ); however, interestingly, the rate of cytomegalovirus-related infections was higher in the basiliximab group when compared with the rATG group ( $17.5 \%$ versus $7.8 \%, P=0.02)$, which contradicts the findings of previous studies. ${ }^{5,22}$ Leukopenia and thrombocytopenia immediately post-transplant were more common in the rATG group, but rates were similar by day 14. Patient and graft survival rates at one year were similar in both groups. Furthermore, an open-label, prospective French study demonstrated similar patient and graft survival rates in low immunologic risk renal transplant recipients when comparing the safety and efficacy of basiliximab $(n=52)$ and rATG $(n=53) .{ }^{22}$ In comparing the two cohorts, there was a lower incidence of adverse effects in the basiliximab cohort than in the rATG cohort for the primary endpoints of thrombocytopenia ( $0 \%$ versus $30.2 \%, P<0.0001$ ), leukopenia (19.2\% versus $51.0 \%, P=0.0007)$, and cytomegalovirus infection $(21.2 \%$ versus $41.5 \%, P=0.025) .{ }^{22}$ However, this study only reached statistical power for its primary endpoint of adverse event rates.

The benefits of rATG over basiliximab are not as clear in some subsets of the transplant population. A retrospective analysis of rATG and basiliximab induction in 88 AfricanAmerican renal transplant recipients, a recognized high-risk group, has been completed. ${ }^{23}$ At baseline, renal transplant recipients in the rATG group spent a longer time waitlisted, had a longer duration of end-stage renal disease, were more sensitized, and were more likely to receive retransplants when compared with the basiliximab group. The number of human leukocyte antigen mismatches, allograft cold ischemia time, and donor age and race was similar between the two groups. No difference was found in patient and graft survival, graft function, and incidence of acute rejection and cytomegalovirus infection between the treatment groups. ${ }^{23}$

\section{rATG induction versus other depleting agents}

Selection of an induction agent is highly dependent upon patient-specific factors along with institution-based preferences and drug availability. In the US, use of lymphocytedepleting agents has steadily risen over the past 10 years, with lymphocyte-depleting agents reported as the most commonly utilized (60\%) induction therapy (25\%), and rATG and alemtuzumab (Campath ${ }^{\circledR}$ ) as the most commonly administered lymphocyte-depleting induction agents. ${ }^{24}$

Although there are multiple ATG products on the market, utilization of eATG $\left(\operatorname{Atgam}^{\circledR}\right)$ has declined due to the improved tolerability and increased efficacy seen with the rATG product. ${ }^{25,26}$ A single-center, randomized, doubleblind trial was conducted to assess the efficacy and safety of rATG versus eATG as an induction agent over a 5-year follow-up period. Seventy-two adult transplant recipients were randomized to receive either $\operatorname{rATG}(n=48)$ as a $1.5 \mathrm{mg} / \mathrm{kg} /$ dose given for up to 7 days or eATG $(\mathrm{n}=24)$ as a $15 \mathrm{mg} / \mathrm{kg} /$ dose given for up to 7 days. ${ }^{26}$ All patients received cyclosporine A (Neoral), azathioprine, and corticosteroids for maintenance immunosuppression, with the exception of retransplants, patients with severe gout needing allopurinol, and patients with end-stage renal disease secondary to an immunologic cause, who were given mycophenolate mofetil instead of azathioprine. At the end of the follow-up period, "event-free survival" was higher in the rATG group than in the eATG group (73\% versus 33\%, P<0.001). ${ }^{26}$ There was a significantly higher graft survival seen in the rATG group when compared with the eATG group (77\% and 54\%, respectively, $P=0.046)$. Patient survival was similar between the two arms. At 5 years, rATG patients had a significantly $(P=0.0073)$ lower incidence of acute rejection ( $8 \%$ ) when compared with eATG patients (34\%), but no statistically significant difference in mean serum creatinine was noted between the two groups. Absolute lymphopenia $(<1,000$ cells $/ \mathrm{mm}^{3}$ ) developed rapidly in both groups, and persisted for almost one year in patients receiving $\mathrm{rATG}$ and for only 14 days in eATG patients, suggesting more profound lymphocyte depletion with rATG. Furthermore, suppression of $\mathrm{CD} 3, \mathrm{CD} 5, \mathrm{CD} 4$, and the $\mathrm{CD} 4 / \mathrm{CD} 8$ ratio was greater in the rATG group than in the eATG group. ${ }^{26}$ In addition, there 
was a higher incidence of malignancy noted in the Atgam group compared with the Thymoglobulin group (21\% versus $6 \%, P=0.01){ }^{26}$

Favorable trends for utilization of rATG over eATG continued at 10-year follow-up in the same study, all indicating increased graft survival and lower rejection rates, with a decreased incidence of malignancy in the rATG cohort when compared with the eATG cohort. ${ }^{25}$ Similar findings from other studies have led to a significant decline in the use of Atgam as an induction agent, with Thymoglobulin now being the preferred product. ${ }^{27}$

Alemtuzumab, a humanized anti-CD52 receptor monoclonal antibody targeting CD52 receptors on both B-cells and T-cells, is increasingly being used off-label as renal transplant induction therapy. Optimal dosing and frequency for induction of renal transplant recipients have not been established. Similar patient and graft survival rates were demonstrated in a prospective, randomized, controlled trial comparing alemtuzumab with conventional (rATG or basiliximab) induction therapy in kidney transplant recipients stratified for risk of rejection. ${ }^{28}$ Patients at low risk of rejection received alemtuzumab or basiliximab induction whereas patients at high risk of rejection received alemtuzumab or rATG induction. All patients received tacrolimus, mycophenolate mofetil, and corticosteroids, with early withdrawal and prophylactic regimens initiated as per institutional protocol. At 12 months' follow-up, the rate of BPAR was lower in the alemtuzumab group when compared with both conventional groups (5\% versus $17 \%, P \leq 0.001) .{ }^{28}$ At 3 -year follow-up, a significantly $(P=0.003)$ lower rate of BPAR was seen with alemtuzumab (10\%) when compared with basiliximab $(22 \%)$, but no difference was seen between alemtuzumab (18\%) when compared with $\mathrm{rATG}(15 \%, P=0.63) .{ }^{28}$ Additionally, a prospective trial randomizing kidney alone, pancreas alone, and kidney-pancreas transplant recipients to either alemtuzumab $(n=48)$ or rATG $(n=50)$ with similar maintenance immunosuppression based on immunologic risk showed similar acute rejection rates. ${ }^{29}$ When comparing kidney alone transplant recipients, graft survival for the alemtuzumab and rATG cohorts was $95 \%$ and $96 \%$, respectively (not statistically significant). ${ }^{29}$ However, there was a significantly higher number of acute rejection episodes in the rATG group than in the alemtuzumab group ( $P=0.007)$, with the majority of rATG rejection episodes occurring in standard criteria donor kidney transplants. At 3 years, a larger study of the same group ( $n=222$ ) revealed similar outcomes, with a lower incidence of BPAR episodes in kidney alone transplant patients receiving alemtuzumab than in those receiving rATG $(12 \%$ versus $27 \%, P=0.03) .{ }^{30}$ Significant differences in infectious complications were observed in both studies. ${ }^{28-30}$ Of note, in 2012, Sanofi voluntarily withdrew alemtuzumab from the US and European markets in preparation for an upcoming relaunch with a new indication for treatment of multiple sclerosis, under the trade name Lemtrada ${ }^{\circledR} .{ }^{31}$

OKT3 (muromonab-CD3) was the first biologic agent used in clinical medicine and is the only nonhumanized antibody approved for use in the treatment of acute renal allograft rejection. ${ }^{3}$ Early evidence suggested that OKT3 was superior to steroids for reversing rejection, which translated into better survival in patients experiencing acute rejection. ${ }^{32,33}$ OKT3 is a mouse-derived monoclonal antibody directed against the CD3 antigen on the surface of T-lymphocytes. The murine monoclonal structure has been shown to promote production of anti-murine antibodies in patients, which can result in tachyphylaxis and anaphylaxis. Immune reactions to OKT3 may be life-threatening, and such reactions can include shock, cardiovascular collapse, cardiac arrest, and respiratory arrest when subsequent doses are administered. ${ }^{34}$ Initial doses must be administered on an inpatient basis under close supervision and may require prophylaxis with glucocorticoids, antihistamines, and acetaminophen. Because newer induction antibodies are efficacious without the risk of life-threatening immune reactions and cumbersome administration requirements, OKT3 has fallen out of favor in kidney transplant induction. Following a decline in market demand, Janssen discontinued production of OKT3 in 2010.

\section{Special populations Pediatric renal transplant recipients}

Data on the comparative efficacy of rATG and other induction regimens are sparser and less clear in pediatric renal transplant recipients. There is no clear consensus on best induction practices in this population. Two retrospective studies evaluated the relative efficacy of no induction and induction with rATG, eATG, or basiliximab in pediatric patients also receiving combination immunosuppressive therapy. ${ }^{35,36}$ The first of the studies, by Khositseth et al, compared $\mathrm{rATG} 1.5 \mathrm{mg} / \mathrm{kg} /$ day for 10 days with eATG $15 \mathrm{mg} / \mathrm{kg} /$ day for 14 days in subjects receiving concomitant corticosteroids, cyclosporine, and mycophenolate mofetil. ${ }^{36}$ Khositseth et al found that rATG induction was associated with significantly lower rates of BCAR $(33 \%$ versus $50 \%, P=0.02$ ) up to 3 years after transplantation in these patients. Median time to BCAR and severity of BCAR were not significant between the treatment groups, 
nor was there any difference in patient survival at the one-year, 2-year, and 3-year follow-up, or in any other measured endpoint or laboratory marker. Findings from a study by Baron et al suggest that the incidence of BCAR at one year post transplant was not significantly different when comparing no induction, rATG induction, and basiliximab induction. Patient and graft survival rates were comparable at one year, but mean glomerular filtration rate in rATG recipients ( $42.4 \mathrm{~mL}$ per minute) was significantly reduced $(P<0.05)$ versus basiliximab $(78.3 \mathrm{~mL}$ per minute) or no induction (66 mL per minute). ${ }^{35}$ Both studies suggest that rATG induction is relatively well tolerated in pediatric patients. ${ }^{35,36}$ There was no difference in incidence of cytomegalovirus infection or post-transplant lymphoproliferative disorder between $\mathrm{rATG}$, eATG, or basiliximab induction, or without induction. ${ }^{36}$ However, there was a significantly increased likelihood of Epstein-Barr virus infection with $\mathrm{rATG}$ induction than with eATG induction ( $8 \%$ versus $3 \%$, respectively, $P=0.002$ ).

\section{Elderly renal transplant recipients}

The choice of induction immunosuppressive agents in elderly transplant recipients has been a matter of constant debate, given the reduced immunogenicity and high risk of infection in this subset of the transplant population. ${ }^{37}$ Very few studies have addressed the selection of induction agents in this population. A retrospective registry analysis using the Organ Procurement Transplantation Network/United Network of Organ Sharing database compared induction with rATG $(n=7,140)$, an interleukin-2 receptor antagonist $(n=6,215)$, and alemtuzumab $(n=1,465)$ in four groups of elderly ( $>60$ years) deceased donor kidney transplant recipients categorized according to recipient and donor risk factors. ${ }^{38}$ Use of rATG was associated with a low risk of rejection and functional graft loss in high-risk recipients (panel reactive antibody $>20 \%$, black race, or prior transplant) with high-risk donors (extended criteria donor, donation after cardiac death, or cold ischemia time $>24$ hours). A lower rejection rate with use of rATG was also noted in low-risk recipients with high-risk donors, but there was no difference in functional graft loss as compared with interleukin-2 receptor antagonists. Prospective comparison of these agents is warranted to compare efficacy versus risk in the elderly population.

\section{HCV-positive renal transplant recipients}

Kidney transplantation in hepatitis $\mathrm{C}$ virus-seropositive $(\mathrm{HCV}+)$ recipients is associated with improved survival compared with staying on dialysis. ${ }^{39}$ Concerns about using rATG in $\mathrm{HCV}+$ patients are related to the possibility of progression of $\mathrm{HCV}$ infection and associated liver disease following enhanced immunosuppression. In an Organ Procurement and Transplantation Network/Scientific Registry of Transplant Recipients analysis, Luan et $\mathrm{al}^{40}$ showed that induction with either depleting or nondepleting antibodies was associated with a $25 \%$ lower risk for mortality in 3,708 $\mathrm{HCV}+$ recipients as compared with those not receiving induction therapy. A significantly reduced hazard ratio (HR) for death among $\mathrm{HCV}+$ renal transplant recipients was apparent 2 years post-transplant $(0.75,95 \% \mathrm{CI}$ $0.61-0.90, P=0.003)$. Risk of death-censored graft failure was not affected by induction therapy, neither were rates of delayed graft function, acute rejection, or graft failure in a subgroup analysis. The risk of death with a functioning graft was significantly reduced by induction therapy (HR 0.71, 95\% CI 0.58-0.86, $P=0.0004$ ). The investigators documented a reduced HR for patient death with the use of depleting antibody induction (OKT3, ATGAM, rATG; HR $0.82,95 \%$ CI $0.69-0.98, P=0.03$ ) and a comparable HR reduction with nondepleting induction (interleukin-2 receptor antagonists; HR $0.79,95 \%$ CI $0.64-0.98, P=0.03) .{ }^{40}$ They noted that the mechanism underlying this reduction in mortality risk was unclear, but was not likely related to differences in kidney graft outcomes, given that no significant differences in rates of acute rejection and death censored graft failure were observed. ${ }^{40}$ Another Scientific Registry of Transplant Recipients analysis observed similar improvements in patient survival among $\mathrm{HCV}+$ recipients given either depleting or nondepleting antibody induction. ${ }^{41}$ These studies suggest that HCV seropositivity should not influence selection of induction agents in renal transplant candidates.

Limited studies have examined the long-term outcomes of HCV-related liver disease after kidney transplantation. Despite comparable outcomes with various induction agents on a short-term basis, one retrospective study that analyzed post-transplant biopsies collected every 5 years suggests better outcomes with lymphocyte-depleting induction agents. ${ }^{42} \mathrm{~A}$ subset analysis $(\mathrm{n}=31)$ revealed a pattern of progressive liver fibrosis in $\mathrm{HCV}+$ renal transplant recipients receiving daclizumab induction as compared with OKT-3 or rATG induction. ${ }^{42}$ However, the bulk of the retrospective data obtained to date suggests better patient and death censored graft survival with the use of induction therapy, both depleting and nondepleting, in $\mathrm{HCV}+$ kidney transplant recipients. ${ }^{40,41,43}$ 


\section{HIV-positive renal transplant recipients}

With the advent of highly active antiretroviral therapy in 1996, the morbidity and mortality associated with human immunodeficiency virus (HIV) infection has decreased dramatically. Historically, HIV was an absolute contraindication to kidney transplantation. However, with increased life expectancy secondary to improved antiretroviral therapy, patients with well managed HIV infection comprise a significant proportion of transplant candidates at many transplant centers. The use of rATG in an HIV-infected individual is controversial. In a prospective observational study of 20 consecutive kidney transplant recipients, profound suppression of CD4+ T-cells from 475 cells per $\mu \mathrm{L}$ to 9 cells per $\mu \mathrm{L}$ was noted after administration of Thymoglobulin in eleven recipients, which successfully reversed rejection. ${ }^{44}$ Use of rATG did not result in a significant increase in opportunistic infections or progression to acquired immunodeficiency syndrome or death, but led to an increased risk of bacterial infection requiring hospitalization. Similarly, in a prospective study of 150 HIV-infected kidney transplant recipients, Stock et al ${ }^{45}$ found that patients who received $\mathrm{rATG}$ had about twice as many serious infections per follow-up year than patients who did not ( 0.9 versus $0.4, P=0.002$ ). In addition, the risk of graft loss (HR 2.5, CI 1.1-5.6) was marginally higher for patients who received rATG. The optimal induction agent needs to be very carefully selected in this population because not only are they at an increased risk of rejection but there is also a concern about an increase in infectious complications. The currently available data suggest restricting rATG to patients at high immunological risk of rejection.

\section{Safety and monitoring}

rATG is generally well tolerated, with adverse reactions ranging in severity but most often manageable and reversible. ${ }^{46-49}$ Acute hypersensitivity reactions and anaphylaxis to $\mathrm{rATG}$ are rare, with the primary risk factor being allergy to the rabbit component of the drug. Serum sickness, on the other hand, has a delayed onset, and may occur 1-3 weeks after administration, with a reported frequency of $7 \%-27 \% .{ }^{46}$ This delayed immune response can present as fever, arthralgia, pruritus, and swelling at the injection site because of a reaction to the protein content of the rabbit serum component of rATG. ${ }^{46}$ Some patients may experience cytokine release syndrome with primary exposure to an rATG dose. The mechanism behind this reaction is thought to be related to a rapid rise in inflammatory cytokines such as interleukin- 8 and tumor necrosis factor-alpha on first exposure to monoclonal and polyclonal antibodies such as rATG. ${ }^{4}$ Patients may develop mild to severe flu-like symptoms, including fever, rash, shivering, nausea, vomiting, diarrhea, malaise, and in severe cases, respiratory failure. Most institutions now routinely premedicate with corticosteroids, diphenhydramine, and acetaminophen to circumvent these reactions.

A central line infusion is the preferred route of administration for rATG due to the risk of venous thrombosis associated with peripheral administration. This risk has been found to be significantly reduced by adding hydrocortisone and heparin to the rATG infusion solution, ${ }^{50}$ facilitating utilization of the drug without central line placement and in outpatient settings. To minimize possible reactions to $\mathrm{rATG}$, the duration of drug infusion is typically 4 hours or longer. Transplant centers that have administered infusions in 4 hours or less have reported a higher incidence of "first-dose syndrome", including adverse events such as dyspnea, shivering, and nausea. ${ }^{27}$

There are no known drug interactions established with rATG. However, as with other immune globulin products, in patients receiving concomitant plasmapheresis and rATG, it should be noted that plasmapheresis may remove the rATG drug product. ${ }^{49,51}$ The percentage of total dose removed is currently unknown; however, administration after a plasmapheresis session may provide the most effect of an rATG dose.

Leukopenia and thrombocytopenia are commonly observed adverse reactions to administration of rATG, given the profound lymphocyte depletion seen with this drug. Concomitant therapy with drugs known to cause hematologic toxicity, including mycophenolate mofetil and valganciclovir $\left(\right.$ Valcyte $\left.^{\circledR}\right)$, can potentiate this risk. Daily monitoring of white blood cell, T-cell, and platelet counts is warranted, with dose adjustment based on the level of depletion. Routine utilization of immune function monitoring assays such as ImmuKnow ${ }^{\circledR}$ is not yet validated. Several studies have suggested an increased risk of cytomegalovirus disease with use of rATG. However, changes in prophylactic agents and regimens for cytomegalovirus may help to minimize this risk.

The Scientific Registry of Transplant Recipients reviewed 41,686 renal transplant recipients for incidence of posttransplant lymphoproliferative disorder over a follow-up period from January 1, 1996 to February 28, 2002. Patients received either no induction therapy or induction therapy with monoclonal or polyclonal antibodies (eATG, rATG, OKT3, daclizumab, basiliximab, Nashville rabbit ATG, or T10B9). There was a significantly increased risk of developing post-transplant lymphoproliferative disorder in those receiving induction therapy compared with those receiving no induction therapy (RR 1.78, $P<0.001) .{ }^{52}$ The incidence of 
post-transplant lymphoproliferative disorder in rATG patients was $5.7 \%$ (RR 3.00, $P=0.001$ ) versus $9 \%$ in eATG patients (RR 1.50, $P=0.1) .{ }^{52}$ Similar findings have been reported from other US databases. ${ }^{53,54}$ However, it should be noted that these databases included all agents, including the older induction agents such as OKT3, and may not necessarily reflect current practice. However, the reported incidence of post-transplant lymphoproliferative disorder in patients receiving rATG is still low, and similar to that for other induction agents. ${ }^{22,25,26}$ In the pediatric population, a higher rate of Epstein-Barr virus infection was found with $\mathrm{rATG}$, but this did not increase the risk of post-transplant lymphoproliferative disorder. ${ }^{35}$ It is imperative to note that several variables, including recipient-specific risk factors, concomitant disease states and drug therapy, and post-transplant medical management may alter this risk. Xenogeneic anti-rabbit antibody formation may occur after exposure to rATG. A few studies have suggested lower drug concentrations secondary to neutralizing antibodies against the drug; however, this has not been shown to affect treatment outcomes or patient and graft survival. ${ }^{53,54}$

During recent years, the kidney transplant population has witnessed an upward trend in incidence of BK virus (BKV) nephropathy, which currently affects approximately $7.5 \%$ of renal transplant recipients. ${ }^{55-57}$ While upwards of $90 \%$ of the general population are benign latent carriers of $\mathrm{BKV}$, reactivation of $\mathrm{BKV}$ in immunosuppressed patients often results in clinically relevant $\mathrm{BKV}$-related disease, including BKV nephropathy. ${ }^{57,58}$ An estimated $50 \%-90 \%$ of renal transplant recipients experience allograft loss within one year of BKV infection progressing to BKV nephropathy, making BKV nephropathy a significant risk factor for poor allograft prognosis. ${ }^{55-57}$

Increasing potency of the immunosuppressive agents since the mid-1990s has paralleled the growing incidence of BKV-associated nephropathy in transplant patients. ${ }^{57,59}$ Immunosuppression is presumed to create a more permissive environment for viral replication. However, the relative potency of an immunosuppressive agent alone should not be used to predict its impact on BKV infection. ${ }^{55,57,60}$ Kidney grafts are infected by BKV more frequently than native kidneys, suggesting that factors other than immunosuppression contribute to the pathogenesis of BKV in renal epithelial cells. ${ }^{60}$ The influence of individual induction agents on development of BKV-associated nephropathy has been explored in numerous studies. ${ }^{61-66}$

Two retrospective registry analyses found that $\mathrm{rATG}$ induction significantly increased the frequency of BKV treatment versus no induction. ${ }^{61,62}$ Along the same lines, a prospective study found higher rates of BKV replication at 6 months post-transplant versus no induction. ${ }^{61}$ However, the data available for the effects of ATG on BKV replication have been inconsistent. ${ }^{16,62-66}$ A prospective, single-arm study found that, when used in the treatment of acute rejection, ATG did not influence BKV markers for replication or development of nephropathy. ${ }^{66}$ One registry analysis found that exposure to human ATG was not associated with a greater need for treatment of $B K V{ }^{62} \mathrm{~A}$ number of other studies could not identify ATG as an independent risk factor for BKV viruria, BKV viremia, or BKV nephropathy. ${ }^{16,64-67}$ While the data suggest that $\mathrm{rATG}$ induction may increase the incidence of $\mathrm{BKV}$-associated disease, additional investigation is warranted.

In the largest alemtuzumab and BKV nephropathy outcomes study performed to date, Theodoropoulos et al retrospectively followed 666 simultaneous pancreas-kidney transplant patients and found that $4.7 \%$ of those who underwent induction with alemtuzumab developed BKV nephropathy. ${ }^{68}$ This rate of BKV nephropathy did not differ significantly from that observed in patients who underwent less potent induction regimens with basiliximab, rATG, or steroids alone. ${ }^{68}$ Previous studies of alemtuzumab induction and risk of BKV nephropathy have yielded both supporting and conflicting data. ${ }^{29,68-74}$ However, unlike most of the earlier studies, Theodoropoulos et al analyzed BKV nephropathy as a coprimary endpoint (along with onset of BK viruria or BK viremia), which strengthens the validity of their findings. ${ }^{68}$ Data from registry analysis and retrospective review indicate that induction with nondepleting agents such as basiliximab and daclizumab does not significantly impact the risk of developing BKV. $55,57,62,70,75$

\section{Cost-effective strategies with thymoglobulin induction}

Optimizing rATG induction regimens can have significant financial implications. The average wholesale price for a five-dose course of rATG is estimated at $\$ 12,750.00$ $(1.5 \mathrm{mg} / \mathrm{kg} \times 5$ doses for a $70 \mathrm{~kg}$ patient $) .{ }^{76}$ Marfo et al conducted a retrospective review of 84 deceased donor kidney transplant recipients who received either short-course rATG of $1.5 \mathrm{mg} / \mathrm{kg}$ for a total of three doses ( $\mathrm{n}=28$; total mean dose $4.6 \mathrm{mg} / \mathrm{kg}$ ) or standard rATG induction therapy of $1.5 \mathrm{mg} / \mathrm{kg}$ for a total of five doses ( $\mathrm{n}=32$; total mean dose $7.3 \mathrm{mg} / \mathrm{kg}) .{ }^{77}$ At 6 months post-transplant, neither BCAR $(17.8 \%$ versus $12.5 \%)$ nor serum creatinine concentration $(1.56 \mathrm{mg} / \mathrm{dL}$ versus $1.85 \mathrm{mg} / \mathrm{dL})$ differed significantly 
between the short-course and standard-course rATG groups, suggesting that shorter-course rATG induction offers cost savings of up to $30 \%$ (\$2,548 per patient in 2011), without negatively impacting rates of graft survival or acute rejection. Moreover, short-course induction appeared to reduce the prevalence of therapy-related leukopenia compared with standard-course induction, although this finding was not statistically significant. CD3+ cell count monitoring has been proposed as a means of determining the minimum necessary cumulative dose of rATG. ${ }^{14,77,78}$ The efficacy of rATG is dependent on T-lymphocyte depletion and functional alteration, and there is evidence of successful dosing and cost minimization guided by CD3+ cell counts. ${ }^{14,78}$ In 2004, eight cardiac transplant recipients were treated with dose-adjusted rATG for induction and acute rejection, to maintain absolute CD3+ cell counts less than 25 cells $/ \mathrm{mm}^{3} .^{78}$ Researchers observed a $60 \%$ reduction in the total dose of rATG administered and a 58\% reduction in total cost. Another study examined the outcomes and pharmacoeconomics of intermittent administration of rATG doses as induction therapy in high-risk kidney and kidney-pancreas transplant recipients. ${ }^{14}$ The first doses of induction therapy were administered intraoperatively, and repeat doses were not given until CD3+ cell counts surpassed 20 cells $/ \mathrm{mm}^{3}$. A calcineurin inhibitor was not initiated as part of the maintenance immunosuppression regimen until serum creatinine levels decreased by at least 25\% from pretransplant levels, and rATG doses were discontinued once serum calcineurin inhibitor concentrations reached the therapeutic target range. This intermittent dosing schedule resulted in average savings of $46 \%$ and $68 \%$, respectively, when compared with standard 6-day and 10-day rATG induction regimens. ${ }^{14}$ Unfortunately, there is no standard threshold for CD3+ cell counts in rATG dose adjustment. Depending on the literature consulted, adjustments may be made based on percent T-cell count from $10 \%$ to $20 \%$ or absolute T-cell counts ranging from 10 cells $/ \mathrm{mm}^{3}$ to 100 cells $/ \mathrm{mm}^{3} .{ }^{14,78}$ Because of this lack of consistency, monitoring of CD3+ cell count has not become standard practice in $\mathrm{rATG}$ induction therapy.

\section{Conclusion}

rATG is a lymphocyte-depleting polyclonal antibody that, when used as induction therapy, effectively reduces rates of BCAR in renal transplant recipients. rATG promotes intense immunosuppression that may be particularly beneficial in patients at high risk for acute allograft rejection, but benefits should be balanced with potential risks. rATG is not approved by the US Food and Drug Administration for transplant induction, and current strategies for use vary widely based on cumulative dose, timing of first dose, and duration of therapy. Alternative induction agents may be broadly categorized as lymphocyte-nondepleting agents (daclizumab and basiliximab) or lymphocyte-depleting agents (eATG and alemtuzumab). Head-to-head comparisons suggest that rATG is more effective than basiliximab at preventing acute rejection in patients at high risk for acute rejection and delayed graft function, with some increased risk of infection. Compared with alternative depleting agents, rATG is better tolerated and more efficacious than eATG; rATG and alemtuzumab equally promote long-term graft survival, but the risk of acute graft rejection and BPAR may be elevated with rATG.

The debate on best practices in special populations is ongoing. rATG appears to be well tolerated in pediatric patients, although there is increased risk of Epstein-Barr virus infection in this population. Elderly patients have reduced immunogenicity and are at greater risk of post-transplant infection, and rATG induction may be best limited to recipients at high risk for rejection and with high-risk donors. Induction therapy of any kind has been shown to substantially improve survival in HCV-positive renal transplant recipients. rATG profoundly suppresses CD4+ T-cells in HIV-infected patients and should be restricted to use in patients at high immunologic risk for rejection.

rATG is well tolerated and adverse reactions are typically manageable and reversible. Immune reactions are common and may be serious, so most institutions premedicate with corticosteroids, diphenhydramine, and acetaminophen. Administration via central line infusion bypasses the risk of venous thrombosis; however, pretreatment with hydrocortisone and heparin also addresses this risk with outpatient peripheral infusion. Due to the risk of leukopenia and thrombocytopenia, white blood cell and platelet counts should be monitored daily, and rATG doses should be adjusted based on the level of depletion. Concomitant cytomegalovirus prophylaxis is recommended due to an increased risk of infectious complications.

rATG induction therapy is relatively expensive. Shortcourse therapy and intermittent dosing regimens have provided cost savings with no negative impact on graft survival or risk of acute rejection. CD3+ cell count monitoring has been proposed as a means to guide dose minimization; however, there are no established thresholds for CD3+ monitoring at this time. A cost-effective strategy in a kidney transplant protocol design including rATG induction should have emphasis on tailoring rATG doses based on the 
renal transplant recipient's immunologic risk for rejection to balance efficacy with treatment-associated risks, such as infection and malignancy.

\section{Disclosure}

All authors have no financial or other significant commercial relationships that may have a direct or indirect interest in the subject matter of the paper.

\section{References}

1. Kasiske BL, Zeier MG, Craig JC, et al. KDIGO clinical practice guideline for the care of kidney transplant recipients. Am J Transplant. 2009;9 Suppl 3:S1-S155.

2. Thymoglobulin(R) (anti-thymocyte globulin-rabbit) package insert. Fremont, CA, USA: SangStat Medical Corporation; 2002.

3. Deeks ED, Keating GM. Rabbit anti-thymocyte globulin (thymoglobulin): a review of its use in the prevention and treatment of acute renal allograft rejection. Drugs. 2009;69(11):1483-1512.

4. Guttmann RD, Caudrelier P, Alberici G, Touraine JL. Pharmacokinetics, foreign protein immune response, cytokine release, and lymphocyte subsets in patients receiving thymoglobuline and immunosuppression. Transplant Proc. 1997;29(7A):24S-26S.

5. Lebranchu Y, Bridoux F, Buchler M, et al. Immunoprophylaxis with basiliximab compared with anti-thymocyte globulin in renal transplant patients receiving MMF-containing triple therapy. Am J Transplant. 2002;2(1):48-56.

6. Mohty M. Mechanisms of action of anti-thymocyte globulin: T-cell depletion and beyond. Leukemia. 2007;21(7):1387-1394.

7. Mourad G, Morelon E, Noel C, Glotz D, Lebranchu Y. The role of Thymoglobulin induction in kidney transplantation: an update. Clin Transplant. 2012;26(5):E450-E464.

8. Noel C, Abramowicz D, Durand D, et al. Daclizumab versus antithymocyte globulin in high-immunological-risk renal transplant recipients. JAm Soc Nephrol. 2009;20(6):1385-1392.

9. Stauch D, Dernier A, Sarmiento Marchese E, et al. Targeting of natural killer cells by rabbit anti-thymocyte globulin and campath- $1 \mathrm{H}$ : similar effects independent of specificity. PLoS One. 2009;4(3):e4709.

10. Agha IA, Rueda J, Alvarez A, et al. Short course induction immunosuppression with thymoglobulin for renal transplant recipients. Transplantation. 2002;73(3):473-475.

11. Goggins WC, Pascual MA, Powelson JA, et al. A prospective, randomized, clinical trial of intraoperative versus postoperative Thymoglobulin in adult cadaveric renal transplant recipients. Transplantation. 2003;76(5):798-802.

12. Shapiro R, Jordan ML, Basu A, et al. Kidney transplantation under a tolerogenic regimen of recipient pretreatment and low-dose postoperative immunosuppression with subsequent weaning. Ann Surg. 2003;238(4):520-525.

13. Gurk-Turner C, Airee R, Philosophe B, Kukuruga D, Drachenberg C, Haririan A. Thymoglobulin dose optimization for induction therapy in high risk kidney transplant recipients. Transplantation. 2008;85(10):1425-1430.

14. Peddi VR, Bryant M, Roy-Chaudhury P, Woodle ES, First MR. Safety, efficacy, and cost analysis of thymoglobulin induction therapy with intermittent dosing based on CD3+ lymphocyte counts in kidney and kidneypancreas transplant recipients. Transplantation. 2002;73(9):1514-1518.

15. Stevens RB, Mercer DF, Grant WJ, et al. Randomized trial of singledose versus divided-dose rabbit anti-thymocyte globulin induction in renal transplantation: an interim report. Transplantation. 2008;85(10): 1391-1399.

16. Wong W, Agrawal N, Pascual M, et al. Comparison of two dosages of thymoglobulin used as a short-course for induction in kidney transplantation. Transplant Int. 2006;19(8):629-635.
17. Charpentier B, Rostaing L, Berthoux F, et al. A three-arm study comparing immediate tacrolimus therapy with anti-thymocyte globulin induction therapy followed by tacrolimus or cyclosporine A in adult renal transplant recipients. Transplantation. 2003;75(6): 844-851.

18. Mourad G, Garrigue V, Squifflet JP, et al. Induction versus noninduction in renal transplant recipients with tacrolimus-based immunosuppression. Transplantation. 2001;72(6):1050-1055.

19. Webster AC, Playford EG, Higgins G, Chapman JR, Craig JC. Interleukin 2 receptor antagonists for renal transplant recipients: a metaanalysis of randomized trials. Transplantation. 2004;77(2):166-176.

20. US Food and Drug Administration. Important Drug Information 2009. Accessed November 22, 2013.

21. Brennan DC, Daller JA, Lake KD, Cibrik D, Del Castillo D. Rabbit anti-thymocyte globulin versus basiliximab in renal transplantation. N Engl J Med. 2006;355(19):1967-1977.

22. Mourad G, Rostaing L, Legendre C, Garrigue V, Thervet E, Durand D. Sequential protocols using basiliximab versus anti-thymocyte globulins in renal-transplant patients receiving mycophenolate mofetil and steroids. Transplantation. 2004;78(4):584-590.

23. Haririan A, Morawski K, Sillix DH, et al. Induction therapy with basiliximab versus Thymoglobulin in African-American kidney transplant recipients. Transplantation. 2005;79(6):716-721.

24. Matas AJ, Smith JM, Skeans MA, et al. OPTN/SRTR 2011 Annual Data Report: kidney. Am J Transplant 2013;13 Suppl 1:11-46.

25. Hardinger KL, Rhee $\mathrm{S}$, Buchanan $\mathrm{P}$, et al. A prospective, randomized, double-blinded comparison of thymoglobulin versus Atgam for induction immunosuppressive therapy: 10-year results. Transplantation. 2008;86(7):947-952.

26. Hardinger KL, Schnitzler MA, Miller B, et al. Five-year follow up of thymoglobulin versus ATGAM induction in adult renal transplantation. Transplantation. 2004;78(1):136-141.

27. Brennan DC, Flavin K, Lowell JA, et al. A randomized, double-blinded comparison of Thymoglobulin versus Atgam for induction immunosuppressive therapy in adult renal transplant recipients. Transplantation. 1999;67(7):1011-1018.

28. Hanaway MJ, Woodle ES, Mulgaonkar S, et al. Alemtuzumab induction in renal transplantation. N Engl J Med. 2011;364(20):1909-1919.

29. Farney A, Sundberg A, Moore P, et al. A randomized trial of alemtuzumab versus anti-thymocyte globulin induction in renal and pancreas transplantation. Clin Transplant. 2008;22(1):41-49.

30. Farney AC, Doares W, Rogers J, et al. A randomized trial of alemtuzumab versus antithymocyte globulin induction in renal and pancreas transplantation. Transplantation. 2009;88(6):810-819.

31. McKee S. Sandofi withdraws Campath in US and EU. PharmaTimes. August 21, 2012. Available from: http://www.pharmatimes.com/ Article/12-08-21/Sanofi_withdraws_Campath_in_US_and_EU.aspx. Accessed Deceember 5, 2013.

32. [No authors listed]. A randomized clinical trial of OKT3 monoclonal antibody for acute rejection of cadaveric renal transplants. Ortho Multicenter Transplant Study Group. N Engl J Med. 1985;313(6):337-342.

33. Cosimi AB, Burton RC, Colvin RB, et al. Treatment of acute renal allograft rejection with OKT3 monoclonal antibody. Transplantation. 1981;32(6):535-539.

34. Orthoclone OKT-3(R) 3 sterile solution (muromonab-CD3) package insert. Raritan, NJ, USA: Ortho Biotech Products, LP; 2003.

35. Baron PW, Ojogho ON, Yorgin P, et al. Comparison of outcomes with low-dose anti-thymocyte globulin, basiliximab or no induction therapy in pediatric kidney transplant recipients: a retrospective study. Pediatr Transplant. 2008;12(1):32-39.

36. Khositseth S, Matas A, Cook ME, Gillingham KJ, Chavers BM. Thymoglobulin versus ATGAM induction therapy in pediatric kidney transplant recipients: a single-center report. Transplantation. 2005;79(8):958-963.

37. Meier-Kriesche HU, Ojo A, Hanson J, et al. Increased immunosuppressive vulnerability in elderly renal transplant recipients. Transplantation. 2000;69(5):885-889. 
38. Gill J, Sampaio M, Gill JS, et al. Induction immunosuppressive therapy in the elderly kidney transplant recipient in the United States. Clin J Am Soc Nephrol. 2011;6(5):1168-1178.

39. Ingsathit A, Kamanamool N, Thakkinstian A, Sumethkul V. Survival advantage of kidney transplantation over dialysis in patients with hepatitis C: a systematic review and meta-analysis. Transplantation. 2013;95(7):943-948.

40. Luan FL, Schaubel DE, Zhang H, et al. Impact of immunosuppressive regimen on survival of kidney transplant recipients with hepatitis C. Transplantation. 2008;85(11):1601-1606.

41. Sureshkumar KK, Thai NL, Marcus RJ. Kidney transplantation in hepatitis C-positive recipients: does type of induction influence outcomes? Transplant Proc. 2012;44(5):1262-1264.

42. Roth D, Gaynor JJ, Reddy KR, et al. Effect of kidney transplantation on outcomes among patients with hepatitis C. J Am Soc Nephrol. 2011;22(6):1152-1160.

43. Vivanco M, Friedmann P, Xia Y, et al. Campath induction in HCV and $\mathrm{HCV} / \mathrm{HIV}$-seropositive kidney transplant recipients. Transplant Int. 2013;26(10):1016-1026.

44. Carter JT, Melcher ML, Carlson LL, Roland ME, Stock PG. Thymoglobulin-associated Cd4+ T-cell depletion and infection risk in HIV-infected renal transplant recipients. Am J Transplant. 2006;6(4): 753-760.

45. Stock PG, Barin B, Murphy B, et al. Outcomes of kidney transplantation in HIV-infected recipients. $N$ Engl J Med. 2010;363(21):2004-2014.

46. Boothpur R, Hardinger KL, Skelton RM, et al. Serum sickness after treatment with rabbit anti-thymocyte globulin in kidney transplant recipients with previous rabbit exposure. Am J Kidney Dis. 2010;55(1):141-143.

47. Kandil E, Alabbas H, Distant D. Anaphylaxis to thymoglobulin: a case report and literature review. J La State Med Soc. 2009;161(5):279-281.

48. Pham PT, Pham PM, Miller JM, Pham PC. Polyclonal antibody-induced serum sickness presenting as rapidly progressive descending paralysis. Transplantation. 2007;83(12):1657.

49. Tanriover B, Chuang P, Fishbach B, et al. Polyclonal antibody-induced serum sickness in renal transplant recipients: treatment with therapeutic plasma exchange. Transplantation. 2005;80(2):279-281.

50. Erickson AL, Roberts K, Malek SK, Chandraker AK, Tullius SG, Gabardi S. Analysis of infusion-site reactions in renal transplant recipients receiving peripherally administered rabbit antithymocyte globulin as compared with basiliximab. Transplant Int. 2010;23(6):636-640.

51. Ipema H, Thielke J, West-Thielke P. Removal of anti-thymocyte globulin (Thymoglobulin) by plasmapheresis in patients undergoing ABO incompatible or positive crossmatch kidney transplant. Presented at the American Transplant Congress, May 1-5, 2010, San Diego, CA, USA.

52. Bustami RT, Ojo AO, Wolfe RA, et al. Immunosuppression and the risk of post-transplant malignancy among cadaveric first kidney transplant recipients. Am J Transplant. 2004;4(1):87-93.

53. Book BK, Pescovitz MD, Agarwal A, et al. In vitro monitoring of in vivo development of human anti-thymoglobulin antibodies by ELISA. Transplant Proc. 2006;38(9):2869-2871.

54. Regan JF, Campbell K, Van Smith L, et al. Sensitization following Thymoglobulin and Atgam rejection therapy as determined with a rapid enzyme-linked immunosorbent assay. US Thymoglobulin Multi-Center Study Group. Transplant Immunol. 1999;7(2):115-121.

55. Akpinar E, Ciancio G, Sageshima J, et al. BK virus nephropathy after simultaneous pancreas-kidney transplantation. Clin Transplant. 2010;24(6):801-806.

56. Lim L, Kay ID, Palladino S, Flexman J. Variability in patterns of BK viral load after renal transplantation. Diagn Microbiol Infect Dis. 2008;61(3):302-308.

57. Suwelack B, Malyar V, Koch M, Sester M, Sommerer C. The influence of immunosuppressive agents on BK virus risk following kidney transplantation, and implications for choice of regimen. Transplant Rev (Orlando). 2012;26(3):201-211.
58. Hirsch HH, Steiger J. Polyomavirus BK. Lancet Infect Dis. 2003;3(10): 611-623.

59. Anzivino E, Bellizzi A, Mitterhofer AP, et al. Early monitoring of the human polyomavirus BK replication and sequencing analysis in a cohort of adult kidney transplant patients treated with basiliximab. Virol J. 2011;8:407.

60. Batal I, Zeevi A, Heider A, et al. Measurements of global cell-mediated immunity in renal transplant recipients with $\mathrm{BK}$ virus reactivation. $\mathrm{Am}$ J Clin Pathol. 2008;129(4):587-591.

61. Dadhania D, Snopkowski C, Ding R, et al. Epidemiology of BK virus in renal allograft recipients: independent risk factors for BK virus replication. Transplantation. 2008;86(4):521-528.

62. Dharnidharka VR, Cherikh WS, Abbott KC. An OPTN analysis of national registry data on treatment of BK virus allograft nephropathy in the United States. Transplantation. 2009;87(7):1019-1026.

63. Beimler J, Sommerer C, Zeier M. The influence of immunosuppression on the development of BK virus nephropathy - does it matter? Nephrol Dial Transplant. 2007;22 Suppl 8:viii66-viii71.

64. Brennan DC, Agha I, Bohl DL, et al. Incidence of BK with tacrolimus versus cyclosporine and impact of preemptive immunosuppression reduction. Am J Transplant. 2005;5(3):582-594.

65. Buehrig CK, Lager DJ, Stegall MD, et al. Influence of surveillance renal allograft biopsy on diagnosis and prognosis of polyomavirus-associated nephropathy. Kidney Int. 2003;64(2):665-673.

66. Hirsch HH, Knowles W, Dickenmann M, et al. Prospective study of polyomavirus type BK replication and nephropathy in renal-transplant recipients. $N$ Engl J Med. 2002;347(7):488-496.

67. Binet I, Nickeleit V, Hirsch HH, et al. Polyomavirus disease under new immunosuppressive drugs: a cause of renal graft dysfunction and graft loss. Transplantation. 1999;67(6):918-922.

68. Theodoropoulos N, Wang E, Penugonda S, et al. BK virus replication and nephropathy after alemtuzumab-induced kidney transplantation. Am J Transplant. 2013;13(1):197-206.

69. Cannon RM, Brock G, Marvin MR, Eng M, Buell JF. Analysis of BK viral infection after alemtuzumab induction for renal transplant. Transpl Infect Dis. 2012;14(4):374-379.

70. Issa NC, Fishman JA. Infectious complications of antilymphocyte therapies in solid organ transplantation. Clin Infect Dis. 2009;48(6): 772-786.

71. Margreiter R, Klempnauer J, Neuhaus P, Muehlbacher F, Boesmueller C, Calne RY. Alemtuzumab (Campath-1H) and tacrolimus monotherapy after renal transplantation: results of a prospective randomized trial. Am J Transplant. 2008;8(7):1480-1485.

72. Plata-Munoz JJ, Vaidya A, Fuggle SV, Friend PJ. Effect of alemtuzumab or basiliximab induction therapy on graft function and survival of kidneys from donors after cardiac death. Transplant Int. 2009;22(10):1024-1027.

73. Schadde E, D'Alessandro AM, Knechtle SJ, et al. Alemtuzumab induction and triple maintenance immunotherapy in kidney transplantation from donors after cardiac death. Transplant Int. 2008;21(7):625-636.

74. Tan HP, Donaldson J, Basu A, et al. Two hundred living donor kidney transplantations under alemtuzumab induction and tacrolimus monotherapy: 3-year follow-up. Am J Transplant. 2009;9(2):355-366.

75. Schold JD, Rehman S, Kayle LK, Magliocca J, Srinivas TR, Meier-Kriesche HU. Treatment for BK virus: incidence, risk factors and outcomes for kidney transplant recipients in the United States. Transplant Int. 2009;22(6):626-634.

76. Micromedex healthcare series. Thompson Healthcare Inclusive; 2011. Available from: http://www.micromedex.com/. Accessed December 5, 2013.

77. Marfo K, Akalin E, Wang C, Lu A. Clinical and economic analysis of short-course versus standard-course anti-thymocyte globulin (rabbit) induction therapy in deceased-donor renal transplant recipients. Am J Health Syst Pharm. 2011;68(23):2276-2282.

78. Uber WE, Uber LA, VanBakel AB, et al. CD3 monitoring and thymoglobulin therapy in cardiac transplantation: clinical outcomes and pharmacoeconomic implications. Transplant Proc. 2004;36(10):3245-3249. 
Transplant Research and Risk Management

Dovepress

\section{Publish your work in this journal}

Transplant Research and Risk Management is an international, peerreviewed open access journal focusing on all aspects of transplantation and risk management to achieve optimal outcomes in the recipient improving survival and quality of life. The journal welcomes submitted papers covering original research, basic science, clinical studies,

reviews \& evaluations, guidelines, expert opinion and commentary, case reports and extended reports. The manuscript management system is completely online and includes a very quick and fair peer-review system, which is all easy to use. Visit http://www.dovepress.com/ testimonials.php to read real quotes from published authors.

Submit your manuscript here: http://www.dovepress.com/transplant-research-and-risk-management-journal 